Research Article

\title{
Preparation of Ca/Al-Layered Double Hydroxides/Biochar Composite with High Adsorption Capacity and Selectivity toward Cationic Dyes in Aqueous
}

\author{
Risfidian Mohadi ${ }^{1,3}$, Neza Rahayu Palapa ${ }^{2}$, Aldes Lesbani ${ }^{2,3, *)}$ \\ ${ }^{1}$ Department of Chemistry, Faculty of Mathematics and Natural Sciences, Universitas Sriwijaya, \\ South Sumatera, Indonesia. \\ ${ }^{2}$ Graduate School, Faculty of Mathematics and Natural Sciences, Universitas Sriwijaya, \\ South Sumatera, Indonesia. \\ ${ }_{3}^{3}$ Research Center of Inorganic Materials and Complexes, Faculty of Mathematics and Natural Sciences, \\ Universitas Sriwijaya, South Sumatera, Indonesia.
}

Received: 28th January 2021; Revised: $6^{\text {th }}$ April 2021; Accepted: $9^{\text {th }}$ April 2021 Available online: 12 $2^{\text {nd }}$ April 2021; Published regularly: June 2021

\section{Abstract}

Widely reports have evaluated the use of biochar (BC) composites to layered double hydroxide (LDH) to adsorb dyes from wastewater. However, its applicability for adsorbing a mixture of cationic dyes such as Malachite green (MG), Rodhamine-B (Rh-B), and Methylene blue (MB), which causes carcinogenic and mutagenic effects on aquatic life, has not been studied. In this work, we compared the performance of CaAl-LDH/BC adsorbent with or without the addition of $\mathrm{BC}$ in the adsorption of cationic dyes. The adsorption study was prepared in a batch system using various temperatures, concentrations, and also contact time. The results of the characterization of $\mathrm{Ca} / \mathrm{Al}-\mathrm{Biochar}$ composite showed the unique diffraction of XRD pattern, and also showed two characteristics of starting materials. Surface area analysis by BET method showed Ca/Al-Biochar composite has a higher surface area than starting material. The results of the adsorption study of MG showed that $\mathrm{Ca} / \mathrm{Al}$-Biochar follows the pseudo-second-order kinetic model. The adsorption capacity of MG on Ca/Al-Biochar was up to $71.429 \mathrm{mg} / \mathrm{g}$ and shows selectivity toward MG in an aqueous solution.

Copyright (C) 2021 by Authors, Published by BCREC Group. This is an open access article under the CC BY-SA License (https://creativecommons.org/licenses/by-sa/4.0).

Keywords: Al-Layered Double Hydroxides; Cationic Dyes; Ca/Al-LDH; Biochar; Composite Materials

How to Cite: R. Mohadi, N.R. Palapa, A. Lesbani (2021). Preparation of Ca/Al-Layered Double Hydroxides/Biochar Composite with High Adsorption Capacity and Selectivity toward Cationic Dyes in Aqueous. Bulletin of Chemical Reaction Engineering \& Catalysis, 16(2), 244-252 (doi:10.9767/bcrec.16.2.10211.244-252)

Permalink/DOI: https://doi.org/10.9767/bcrec.16.2.10211.244-252

\section{Introduction}

The dyes are dissolved organic compounds. Dyes have high solubility in water that is difficult to remove by conventional methods [1]. Dyes are used in various industries, such as:

* Corresponding Author.

Email: aldeslesbani@pps.unsri.ac.id (A.Lesbani) textiles, plastics, papers, pharmaceuticals, and cosmetics. Dyes are an essential type of pollutants in industrial wastewater and cause serious environmental problems [2]. The effect of dyes includes a threat to human health owing to mutagenic and carcinogenic [3]. Various methods for dye removal in the aquatic environment were attempted, such as: 
adsorption, coagulation / flocculation, photocatalytic decolorization, microbial decomposition, and electrochemical methods [4-7].

Among these methods, adsorption has been reported to be the most effective method, which has a relatively economical, flexible, and simple design, easy in operation, and efficient for the treatment of dyes on wastewater. The effectivity of the adsorption process is related to the quality and properties of the adsorbent. Several adsorbents have been used for the removal of dyes from wastewater [8]. Adsorbents that can be used to adsorb dyes from wastewater include activated carbon, algae, alumina-MOF, sawdust modification, kaolin, bentonite, and layered double hydroxide (LDH) [9-11]. However, LDH is a favored adsorbent due to its low cost, high stability, low toxicity, reusability, and facile synthesis. The $\mathrm{LDH}$ is a two-dimensional (2D) nanostructured material also termed anionic clay or hydrotalcite. The chemical composition of $\mathrm{LDH}$ is generally represented as:

$\left[\mathrm{M}^{2+}{ }_{1-\mathrm{x}} \mathrm{M}^{3+}{ }_{\mathrm{x} \cdot} \cdot(\mathrm{OH})_{2}\right]^{\mathrm{x}+}\left[\left(\mathrm{A}^{\mathrm{n}-}\right) \cdot \mathrm{mH}_{2} \mathrm{O}\right]^{\mathrm{x}}$

where $\mathrm{M}^{2+}$ and $\mathrm{M}^{3+}$ represent bivalent and trivalent cations respectively, while, $\mathrm{A}^{\mathrm{n}-}$ are interlayer anions. Another aspect favoring the use of $\mathrm{LDH}$ as adsorbents for anionic dyes is their simple intercalation and modification techniques, enhancing their removal efficiency [12].

Removal of dyes by LDH has been reported by many researchers. There are two types of dyes, namely anionic (methyl orange) and cationic (crystal violet), which are used to study the ability of Ni/Al LDH in removing dyes in an aqueous solution [13]. The granular structure of $\mathrm{LDH}$ can limit the adsorption capacity. Biochar (BC) can assist maximize the work of LDH in removing pollutants. Li et al. [14] were reported that the precipitation to composite preparation as adsorbent consisted of core-shell $\mathrm{Fe}_{3} \mathrm{O}_{4}$-LDHs. The kinetics study results from the adsorption process of congo red dye using composite $\mathrm{MgFe}$ showed a significant maxi- mum capacity of around $9127.08 \mathrm{mg} / \mathrm{g}$ [15]. Research conducted by Meili et al. [16] utilizes a composite of MgAl-LDH with $\mathrm{BC}$ to remove cationic dyes in an aqueous solution. This adsorption process obtained a higher maximum capacity at $323 \mathrm{~K}$ of $406.47 \mathrm{mg} / \mathrm{g}$ and achieved equilibrium up to 20 minutes with an adsorption ability reaching $95 \%$ at $\mathrm{pH} 12$. As similarly reported by Palapa et al. [11] using a composite of $\mathrm{CuAl}-\mathrm{BC}$ for the adsorption of Malachite green (MG) reaching equilibrium at 40 minutes with an adsorbed concentration of $108.96 \mathrm{mg} / \mathrm{L}$.

Among all these literature research have been studied, the adsorption of the dyes have been studied widely, but in this research, the preparation of $\mathrm{Ca} / \mathrm{Al} \mathrm{LDH}$ and its composite with $\mathrm{BC}$ to form $\mathrm{Ca} / \mathrm{Al}$-Biochar is used to remove the mixture cationic dyes in aqueous solution to compare the competitive ones to adsorb more into Ca/Al-Biochar. The competition of adsorbed dyes will be studied in selectivity adsorption. Various conditions of the process of adsorption were studied, such as: dye mixture selectivity, times adsorption, dye concentration, and temperature adsorption. The mixture adsorption selectivity was carried out using cationic dyes, i.e. MG, Rhodamine-B (Rh-B), and methylene blue (MB), as shown in Figure 1. The kinetics of adsorption, isotherm, and thermodynamics of the adsorption process of dye using $\mathrm{Ca} / \mathrm{Al} \mathrm{LDH}, \mathrm{BC}$, and $\mathrm{Ca} / \mathrm{Al}$-Biochar will be discussed in this article.

\section{Materials and Methods}

\subsection{Chemical and Instrumentations}

The chemicals, such as: calcium(II) nitrate, aluminum(II) nitrate, and sodium hydroxide, were analytical grade (p.a) from Merck and Sigma-Aldrich. Water was supplied from the Research Center of Inorganic Materials and Complexes FMIPA Universitas Sriwijaya. The purified water was obtained after cycling proses using Purite ${ }^{\circledR}$ ion water purification system. Characterization of materials was

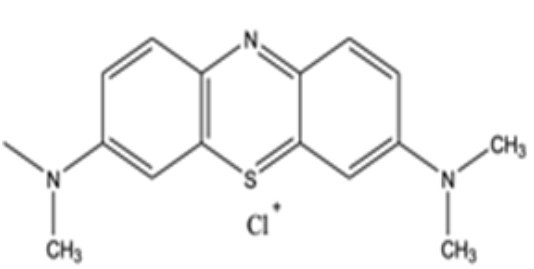

A

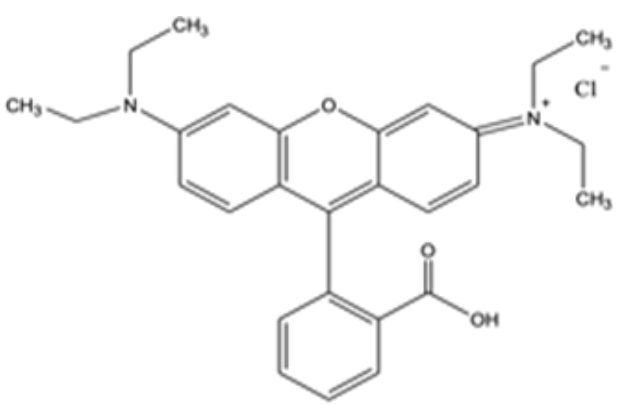

B

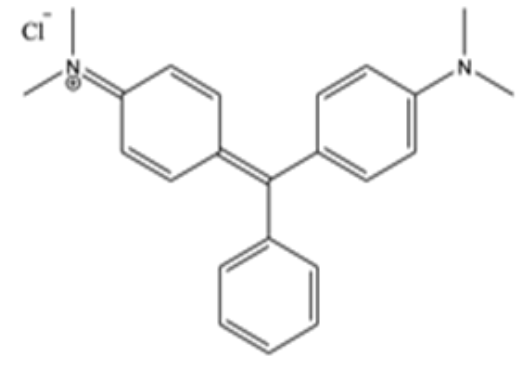

C

Figure 1. Chemical structure of cationic dyes: $M B(A), R h-B(B)$, and MG (C). 
conducted using XRD Rigaku miniflex-6000. Materials were scanned from 5-80 degrees at a scan speed $1 \mathrm{deg} / \mathrm{min}$. Functional groups were analyzed using FT-IR Shimadzu Prestige-21 at wavenumber $400-4000 \mathrm{~cm}^{-1}$ using $\mathrm{KBr}$ pellet. Adsorption-desorption of $\mathrm{N}_{2}$ was conducted using Quantachrome Micrometic ASAP. The concentration of dyes was measured using Spectrophotometer UV-Visible Biobase BK-UV 1800 PC.

\subsection{Biochar Preparation}

Rice husk-BC was produced through thermal treatment of the rice husk; the thermal treatment was carried out in a furnace at 873 $\mathrm{K}$ under nitrogen flow $(283 \mathrm{~K} / \mathrm{min})$ for two hours. Thereafter, the reactor was cooled down and the prepared $\mathrm{BC}$ was characterized. The $\mathrm{BC}$ thus prepared was used in the preparation of composites material and the adsorption experiments.

\subsection{Preparation of $\mathrm{Ca} / \mathrm{Al}-\mathrm{LDH}$}

$\mathrm{Ca} / \mathrm{Al} \mathrm{LDH}$ was synthesized using the coprecipitation method. A $100 \mathrm{~mL}$ of calcium(II) nitrate 0.75 molar was mixed with $100 \mathrm{~mL}$ of aluminum(II) nitrate. The mixture was stirred for an hour and $\mathrm{pH}$ was adjusted using $\mathrm{NaOH} 2$ $\mathrm{M}$ until 10. The reaction was kept at $333 \mathrm{~K}$ for 12 hours to form $\mathrm{Ca} / \mathrm{Al} \mathrm{LDH}$. The solid material was filtered and washed with water then dried at $373 \mathrm{~K}$ overnight.

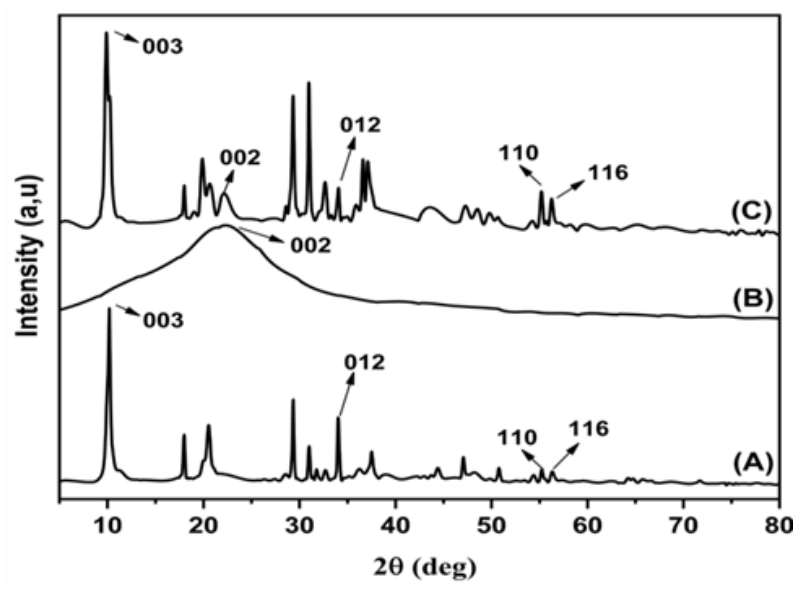

Figure 2. XRD powder patterns of $\mathrm{Ca} / \mathrm{Al} \mathrm{LDH}$ (A), BC (B), and Ca/Al-Biochar (C).

\subsection{Preparation of Ca/Al-Biochar}

The preparation of $\mathrm{Ca} / \mathrm{Al}$-Biochar was carried out by calcium(II) nitrate $10 \mathrm{~mL}$ and aluminum(II) nitrate $10 \mathrm{~mL}$ with a molar ratio $3: 1$. In other beakers, a three $\mathrm{g}$ of rice husk $\mathrm{BC}$ was dissolved by $10 \mathrm{~mL}$ water. The metal salt solution was added to $\mathrm{BC}$ solution. The $\mathrm{pH}$ of the mixture was adjusted to 10 by addition $2 \mathrm{M}$ sodium hydroxide. The reaction was stirred at $333 \mathrm{~K}$ for three days. The composite was filtered and dried at room temperature overnight.

\subsection{Adsorption Selectivity Study}

The selectivity adsorption process of dyes was carried out by $20 \mathrm{~mL}$ of mixtures dyes (MG, MB, Rh-B) with $2 \mathrm{mg} \mathrm{Ca} / \mathrm{Al}$ and $\mathrm{Ca} / \mathrm{Al}-$ Biochar, respectively. The reaction was stirred for several minutes and concentration of each dye was analyzed by UV-Vis spectrophotometer. The adsorption process was studied by variation of adsorption times, initial concentrations, and adsorption temperatures using maximum adsorption amount of dye in the selectivity study. The variation of adsorption times was conducted at 5-180 minutes. The variation of concentrations was studied at $50,60,70,80$, and $90 \mathrm{mg} / \mathrm{L}$ of dye. Variation of adsorption temperatures was carried out at $303,313,323$, and $333 \mathrm{~K}$. Concentration of dye on the solution was analyzed using UV-Vis spectrophotometer.

\section{Results and Discussion}

XRD powder pattern of adsorbent was presented in Figure 2. The diffraction peak of $\mathrm{Ca} / \mathrm{Al}$-Biochar shows the characteristic of $\mathrm{Ca} / \mathrm{Al}$ LDH according to JCPDS 31-0245 and broad diffraction of $\mathrm{BC}$. The characteristic of $\mathrm{Ca} / \mathrm{Al}$ LDH was denoted with reflection (003), (006), (012), (110), and (116), which was indicated the interlayer space of LDH at (003). According to Palapa et al. [17] the reflections of (003), (006), and (110) were essential characteristics to determine a crystallographic parameter. The interlayer space at (003) indicates the composites of $\mathrm{BC}$ took place on the interlayer and surface was increased from $8.42 \AA$ (Ca/Al LDH) to 9.00

Table 1. Surface area properties of materials.

\begin{tabular}{lcccc}
\hline Materials & $\begin{array}{c}\text { Surface Area } \\
\left(\mathrm{m}^{2} / \mathrm{g}\right)\end{array}$ & $\begin{array}{c}\text { Pore VolumeвJн } \\
\left(\mathrm{cm}^{3 / \mathrm{g}}\right)\end{array}$ & $\begin{array}{c}\text { Pore DiameterвJн } \\
(\mathrm{nm})\end{array}$ & $\begin{array}{c}\text { Interlayer d } \mathrm{d}_{(003)} \\
(\AA)\end{array}$ \\
\hline $\mathrm{Ca} / \mathrm{Al} \mathrm{LDH}$ & 29.333 & 0.0072 & 13.033 & 8.42 \\
$\mathrm{BC}$ & 50.936 & 0.00475 & 12.089 & - \\
$\mathrm{Ca}-\mathrm{Al}-\mathrm{LDH} / \mathrm{BC}$ & 158.291 & 0.0174 & 12.474 & 9.00 \\
\hline
\end{tabular}


$\AA$ (Ca/Al-Biochar). The increase of interlayer distance was also related to the increased surface area. The surface area analysis was listed in Table 1.

The surface area and pore analyses were determined using BET and BJH method, respectively. The surface area after formation of Ca/Al-Biochar composites was increasing fifth-fold from $29.333 \mathrm{~m}^{2} / \mathrm{g}$ to $158.291 \mathrm{~m}^{2} / \mathrm{g}$. The increased interlayer of $\mathrm{Ca} / \mathrm{Al} \mathrm{LDH}$ was related to the characteristic of starting materials. The $\mathrm{BC}$ has high surface area properties, which can reduce the agglomeration of LDH [18]. Besides, the decrease in pore diameter and increase the pore volume occurs due to the composites of $\mathrm{BC}$ particles within the LDH layers. This can be attributed to the intercalation of $\mathrm{BC}$ within the $\mathrm{LDH}$ layers, leading to the formation of larger pores, which can act as active binding sites [19].

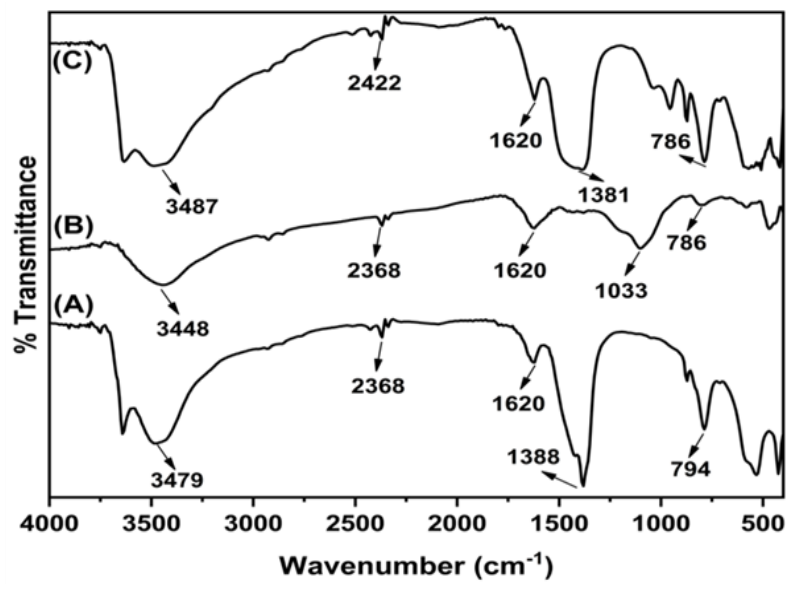

Figure 3. FTIR Spectrum of Ca/Al LDH (A), $\mathrm{BC}(\mathrm{B})$, and $\mathrm{Ca} / \mathrm{Al}-\mathrm{Biochar}(\mathrm{C})$.

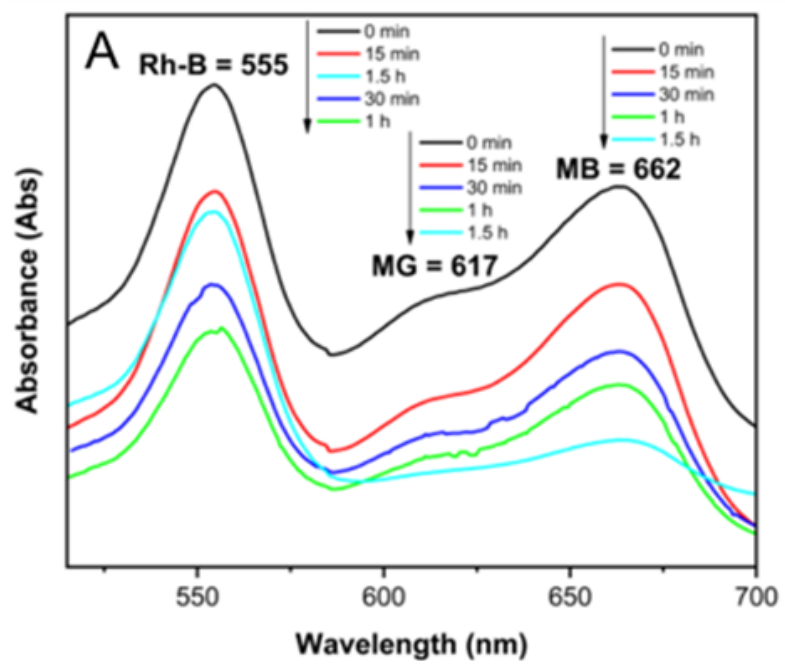

FT-IR spectra for $\mathrm{Ca} / \mathrm{Al} \mathrm{LDH}, \mathrm{BC}$ and Ca/Al-Biochar were shown in Figure 3. The FTIR spectra of $\mathrm{Ca} / \mathrm{Al} \mathrm{LDH}$ and $\mathrm{Ca} / \mathrm{Al}$-Biochar showed a similar spectrum. The characteristic of $\mathrm{Ca} / \mathrm{Al} \mathrm{LDH}$ has intense nitrate bending at $1381 \mathrm{~cm}^{-1}$. The stretching and bending vibrations of $\mathrm{OH}^{-}$from $\mathrm{H}_{2} \mathrm{O}$ were found at wavenumber $3480 \mathrm{~cm}^{-1}$ and $1620 \mathrm{~cm}^{-1}$, respectively. Thus, the vibrations of $\mathrm{M}^{2+}$ and $\mathrm{M}^{3+}$ were indicated at under $800 \mathrm{~cm}^{-1}$. The unique vibration of $\mathrm{BC}$ appeared at $1103 \mathrm{~cm}^{-1}$, which was denoted as a silicate-oxide and at $470 \mathrm{~cm}^{-1}$ as aluminum-oxide.

The performance of $\mathrm{Ca} / \mathrm{Al} \mathrm{LDH}, \mathrm{BC}$ and $\mathrm{Ca} / \mathrm{Al}$-Biochar as selective adsorbents was tested to remove dye mixtures. In addition, the selective adsorption from the mixtures was important to determine the adsorption capacity and active sites adsorbent. Therefore, mixing three cationic dyes on aqueous solution, i.e. MG, MB, and Rh-B, were studied for the adsorption experiments by $\mathrm{Ca} / \mathrm{Al} \mathrm{LDH}, \mathrm{BC}$ and $\mathrm{Ca} / \mathrm{Al}$-Biochar, which are presented in Figure 4.

MG was more adsorbed from mixtures solution using $\mathrm{Ca} / \mathrm{Al} \mathrm{LDH}$ after $90 \mathrm{~min}$, while MB and Rh-B showed slightly decreased adsorption after $90 \mathrm{~min}$. Thus, Ca/Al-Biochar exhibited high selectivity for cationic dyes actually for MG. MG was removed entirely at $90 \mathrm{~min}$. This phenom indicated that the larger surface area of $\mathrm{Ca} / \mathrm{Al}-\mathrm{Bioch}$ ar than pristine LDH affected the adsorption of cationic MG. Also, the moderate adsorption ability for Rh-B and $\mathrm{MB}$ than MG is probably caused by the larger size of Rh-B than MG and MB. In another case, as reported by Wan et al. [20], the presence of $\mathrm{pH}$ can be affected the

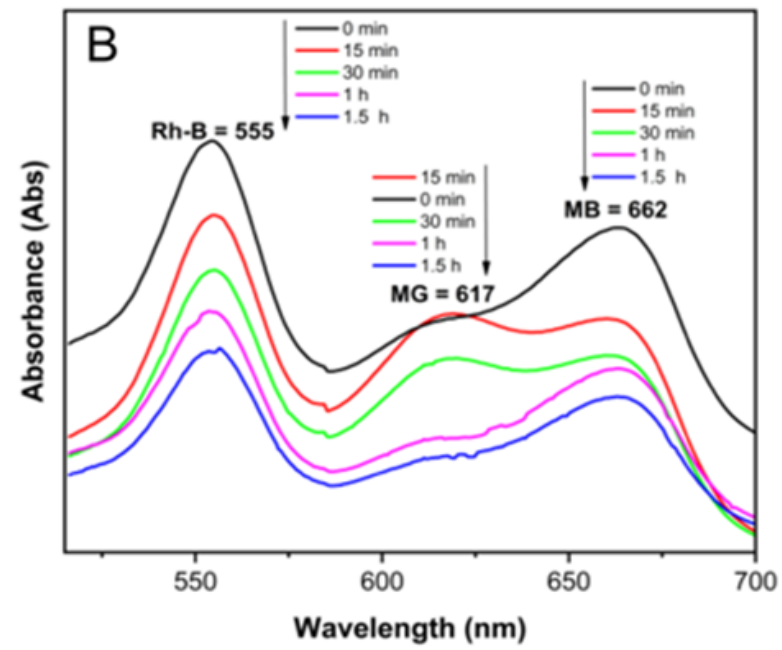

Figure 4. Adsorption selectivity of cationic dyes mixtures adjusted at $\mathrm{pH} 7$ in various adsorption time (A) $\mathrm{Ca} / \mathrm{Al} \mathrm{LDH}$ and (B) $\mathrm{Ca} / \mathrm{Al}$-Biochar. 
selectivity of adsorption in a mixture between MB and MG due to cationic dyes which have positive charges and LDH has positive charges which did not favor the adsorption of positively charged dye cations due to electrostatic repulsion. Therefore, $\mathrm{Ca} / \mathrm{Al}-\mathrm{Biochar}$ showed good adsorption ability and selectivity toward MG on aqueous solutions.

Furthermore, MG was selected as a representative dye to determine adsorption study in an aqueous solution. Firstly, the adsorption process was tested in several $\mathrm{pH}$ conditions, acid until base conditions as presents in Figure 5. The effect of $\mathrm{pH}$ condition on $\mathrm{Ca} / \mathrm{Al} \mathrm{LDH}$ showed that acid or base conditions did not affect dye adsorbed. However, on $\mathrm{Ca} / \mathrm{Al}$-Biochar, it was increased sharply until $\mathrm{pH} 6$ and decreased remarkably in base condition. The value of MG adsorbed onto Ca/Al-Biochar uptake $180 \mathrm{mg} / \mathrm{g}$ at $\mathrm{pH} 6$. According to Das et al. [19] the increasing dye adsorbed was due to surface-active charge of materials and electrostatic bonds between surface and dye molecule.

The adsorption process has studied the effect of time adsorption, temperature and initial concentration. The adsorption process was set between $\mathrm{pH}$ 6-7 for all materials. The effect of adsorption times was calculated using

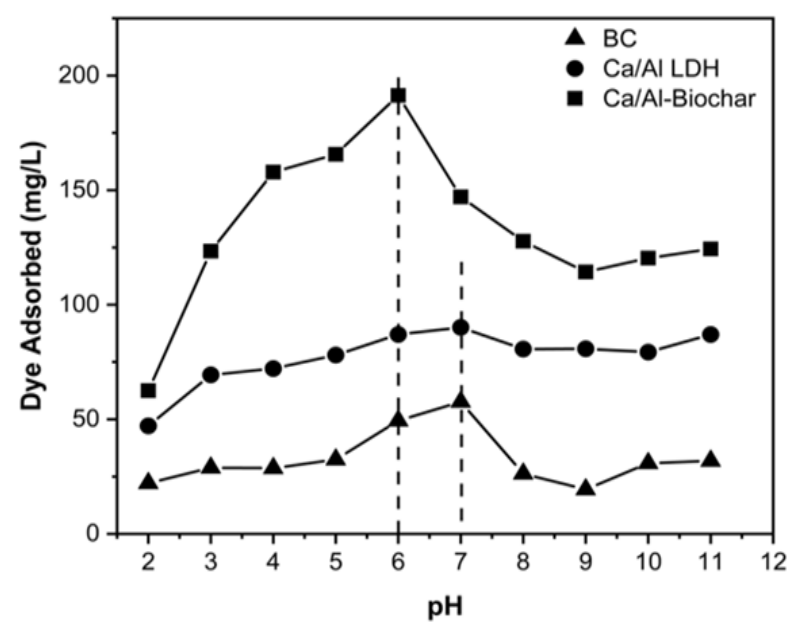

Figure 5. Effect of $\mathrm{pH}$ of $\mathrm{MG}$ adsorption on $\mathrm{Ca} / \mathrm{Al} \mathrm{LDH}, \mathrm{BC}$, and $\mathrm{Ca} / \mathrm{Al}-\mathrm{Biochar}$. kinetic parameter models, i.e. pseudo first order (PFO) and pseudo second order (PSO). Figure 6 was presented the MG adsorbed capacity $v s$. contact time adsorption, which was calculated using PFO and PSO models. The equations were described as:

$$
\begin{aligned}
& \log \left(q_{e}-q_{t}\right)=\log q_{e}-\left(\frac{k_{1}}{2.303}\right) t \\
& \frac{t}{q_{t}}=\frac{1}{k_{2} q_{e}^{2}}+\frac{1}{q_{e}} t
\end{aligned}
$$

where, $q_{e}$ is dye adsorbed capacity at equilibrium $(\mathrm{mg} / \mathrm{g}) ; q_{t}$ is dye adsorbed capacity at times $(\mathrm{mg} / \mathrm{g}) ; t$ is time adsorption $(\mathrm{min}) ; k_{1}$ is kinetic adsorption rate at PFO $\left(\mathrm{min}^{-1}\right) ; k_{2}$ is adsorption kinetic rate at PSO (g/mg.min).

Figure 6 showing the dye uptake increased rapidly for these materials after 90 minutes then reached equilibrium. The higher $\mathrm{MG}$ uptake onto Ca/Al-Biochar had an adsorption capacity $75.190 \mathrm{mg} / \mathrm{g}$. The MG adsorption capacity of $\mathrm{Ca} / \mathrm{Al} \mathrm{LDH}$ was $52.598 \mathrm{mg} / \mathrm{g}$, as similarly reported as Wan et al. [20]. The increasing dye adsorbed capacity on composite was caused by the higher surface area and interlayer space for the composite material. The kinetic parameter was presented in Figure 6 and Table 2 following Eq. 1 and 2. Table 2

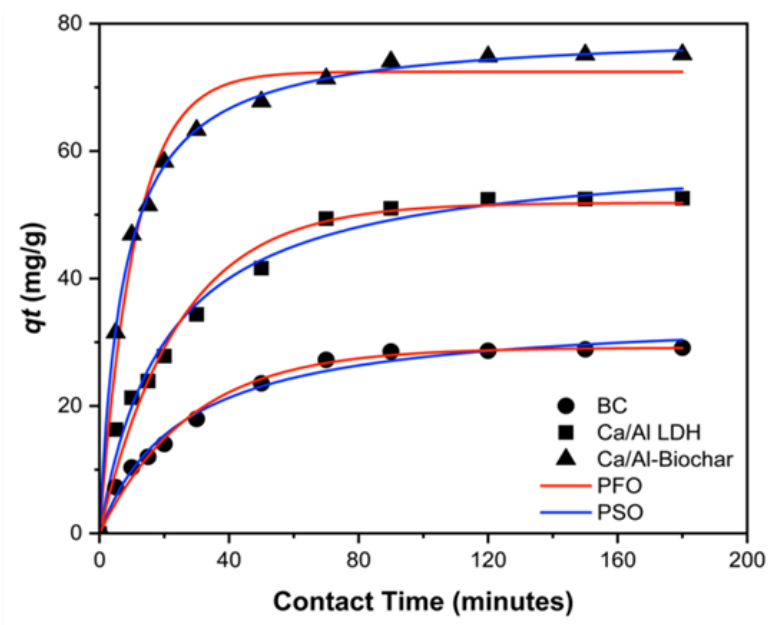

Figure 6. Effect of adsorption time and kinetic adsorption model.

\begin{tabular}{|c|c|c|c|c|c|c|c|c|}
\hline \multirow[b]{2}{*}{ Adsorbents } & \multirow{2}{*}{$\begin{array}{c}\text { Initial } \\
\text { Concentration } \\
(\mathrm{mg} / \mathrm{L})\end{array}$} & \multirow{2}{*}{$\begin{array}{l}Q e_{\text {experiment }} \\
(\mathrm{mg} / \mathrm{g})\end{array}$} & \multicolumn{3}{|c|}{$\mathrm{PFO}$} & \multicolumn{3}{|c|}{$\mathrm{PSO}$} \\
\hline & & & $\begin{array}{l}Q e_{\text {Calc }} \\
(\mathrm{mg} / \mathrm{g})\end{array}$ & $\mathrm{R}^{2}$ & $k_{1}$ & $\begin{array}{l}Q \mathrm{e}_{\text {Calc }} \\
(\mathrm{mg} / \mathrm{g})\end{array}$ & $\mathrm{R}^{2}$ & $k_{2}$ \\
\hline $\mathrm{Ca} / \mathrm{Al} \mathrm{LDH}$ & 99.251 & 52.598 & 50.711 & 0.983 & 0.037 & 22.941 & 0.986 & 0.002 \\
\hline $\mathrm{BC}$ & 99.251 & 29.132 & 26.509 & 0.998 & 0.002 & 33.445 & 0.995 & 0.001 \\
\hline Ca/Al-Biochar & 99.251 & 75.190 & 50.153 & 0.982 & 0.041 & 78.125 & 0.9988 & 0.002 \\
\hline
\end{tabular}

Table 2. Adsorption kinetic parameter. 
indicated the kinetic adsorption process belongs to PSO based on coefficient correlation $\left(\mathrm{R}^{2}\right)$. Besides, this process denotes that electrostatic bonds between the dye molecule
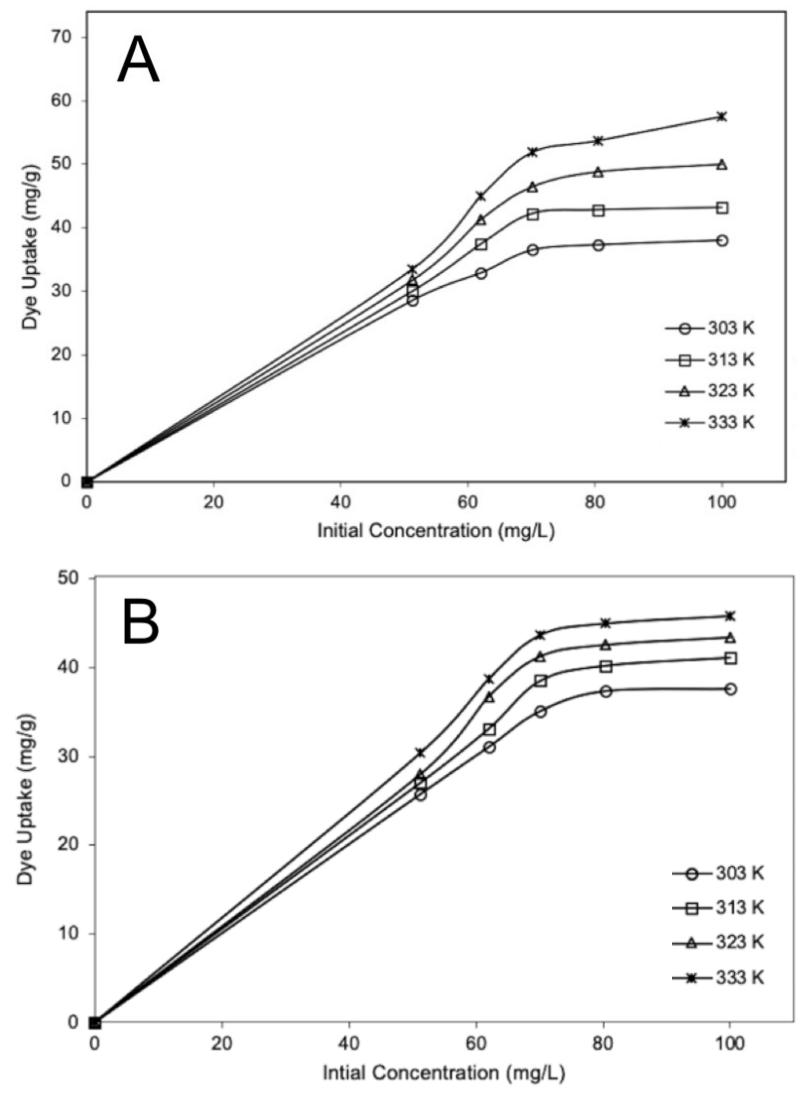

and adsorbent were occurred and indicated the adsorption process was chemisorption [21]. However, this adsorption process should be supported using other adsorption parameters such as isotherm adsorption model and thermodynamic parameters.

To investigate isotherm adsorption, the adsorption process was carried out using several initial concentrations and temperatures. Furthermore, the Langmuir parameter can be used to predict if the adsorption was favorable or not. The parameter had two models, which were calculated by plotting $q_{e}$ vs. $C_{e}$ in several adsorbents with the same concentration as presented data in Figure 7. Figure 7 showing the slightly increasing dye adsorbed capacity

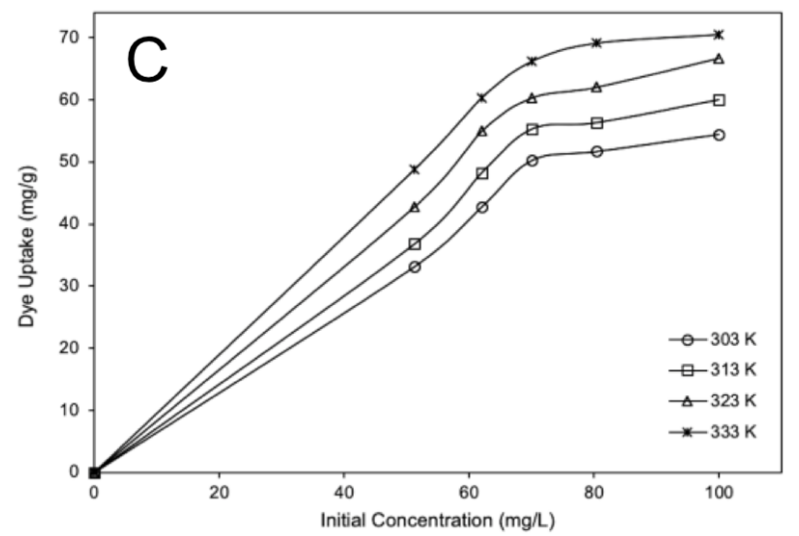

Figure 7. Effect of initial concentration and temperature (A) $\mathrm{Ca} / \mathrm{Al} \mathrm{LDH}$, (B) $\mathrm{BC}$ and (C) $\mathrm{Ca} / \mathrm{Al}$ Biochar.

Table 3. Isotherm Freundlich and Langmuir models.

\begin{tabular}{|c|c|c|c|c|c|c|}
\hline \multirow{2}{*}{ Adsorbents } & \multirow{2}{*}{$\begin{array}{l}\text { Adsorption } \\
\text { Isotherm }\end{array}$} & \multirow{2}{*}{$\begin{array}{c}\text { Adsorption } \\
\text { Constant }\end{array}$} & \multicolumn{4}{|c|}{$\mathrm{T}(\mathrm{K})$} \\
\hline & & & 303 & 313 & 323 & 333 \\
\hline \multirow{6}{*}{$\mathrm{Ca} / \mathrm{Al} \mathrm{LDH}$} & Langmuir & $Q_{\max }$ & 43.860 & 58.480 & 53.476 & 70.423 \\
\hline & & $k_{\mathrm{L}}$ & 0.112 & 0.050 & 0.302 & 0.110 \\
\hline & & $\mathrm{R}^{2}$ & 0.995 & 0.999 & 0.999 & 0.997 \\
\hline & Freundlich & $n$ & 2.456 & 2.707 & 10.571 & 3.717 \\
\hline & & $k_{\mathrm{F}}$ & 8.145 & 9.709 & 34.770 & 21.380 \\
\hline & & $\mathrm{R}^{2}$ & 0.979 & 0.999 & 0.899 & 0.934 \\
\hline \multirow{6}{*}{$\mathrm{BC}$} & Langmuir & $Q_{\max }$ & 45.045 & 44.444 & 48.780 & 51.020 \\
\hline & & $k_{\mathrm{L}}$ & 0.083 & 0.219 & 0.152 & 0.175 \\
\hline & & $\mathrm{R}^{2}$ & 0.986 & 0.999 & 0.990 & 0.991 \\
\hline & Freundlich & $n$ & 1.012 & 9.872 & 13.680 & 15.361 \\
\hline & & $k_{\mathrm{F}}$ & 1.046 & 27.352 & 32.412 & 35.392 \\
\hline & & $\mathrm{R}^{2}$ & 0.999 & 0.905 & 0.942 & 0.945 \\
\hline \multirow{6}{*}{$\begin{array}{c}\text { Ca/Al- } \\
\text { Biochar }\end{array}$} & Langmuir & $Q_{\max }$ & 67.114 & 63.694 & 70.922 & 71.429 \\
\hline & & $k_{\mathrm{L}}$ & 0.100 & 0.394 & 0.445 & 3.256 \\
\hline & & $\mathrm{R}^{2}$ & 0.991 & 0.998 & 0.999 & 0.999 \\
\hline & Freundlich & $n$ & 8.928 & 7.962 & 7.981 & 32.154 \\
\hline & & $k_{\mathrm{F}}$ & 35.522 & 37.757 & 43.063 & 63.709 \\
\hline & & $\mathrm{R}^{2}$ & 0.999 & 0.999 & 0.999 & 0.967 \\
\hline
\end{tabular}


with increasing temperature indicated that the adsorption process was favored at high temperature. The calculation results of the coefficient correlation, which was identified that the Langmuir model was better fitted than the Freundlich model for composite material as presented in Table 3 . These results suggest that the surfaces of adsorbents were homogeneous with the adsorption mechanism of monolayer process. The higher maximum adsorption capacity was obtained by $\mathrm{Ca} / \mathrm{Al}$ Biochar $(71.429 \mathrm{mg} / \mathrm{g})$ than $\mathrm{Ca} / \mathrm{Al} \mathrm{LDH}(70.423$ $\mathrm{mg} / \mathrm{g})$ and $\mathrm{BC}(51.020 \mathrm{mg} / \mathrm{g})$. The $\mathrm{MG}$ adsorption capacity of $\mathrm{Ca} / \mathrm{Al}-\mathrm{Biochar}$ was relatively higher than pristine materials. Further experiments confirm that the modification of $\mathrm{Ca} / \mathrm{Al} \mathrm{LDH}$ with $\mathrm{BC}$ significantly increased the dye removal due to the synergetic effect of $\mathrm{BC}$ and $\mathrm{Ca} / \mathrm{Al}$ in the composite. A presented in Table 4, several adsorbents were tested as MG removal agents. Among these adsorbents, $\mathrm{Ca} / \mathrm{Al} \mathrm{LDH} / \mathrm{BC}$ in our research had in the middle results of others researches but the advantages of this study were high surface area properties of composite and simple preparation methods to obtain Ca/Al-Biochar composite.

Effect of temperature on the adsorption process of MG onto $\mathrm{Ca} / \mathrm{Al} \mathrm{LDH}, \mathrm{BC}$ and $\mathrm{Ca} / \mathrm{Al}$ Biochar were shown in Figure 7 indicating the thermodynamic parameters. The thermodynamic parameters of the adsorption process such as a change in standard free energy $(\Delta G)$, enthalpy $(\Delta H)$, and entropy $(\Delta S)$ were obtained from experiments at various temperatures using the following equations:

$$
\begin{aligned}
& \Delta G=-R T \ln K \\
& \ln K=\frac{\Delta S}{R}-\frac{\Delta H}{R T}
\end{aligned}
$$

where $K$ is the distribution coefficient; $R$ is the gas constants; $T$ is temperature adsorption absolute $(\mathrm{K}) ; \Delta H$ is Enthalpy $(\mathrm{kJ} / \mathrm{mol}) ; \Delta S$ is entropy $(\mathrm{J} / \mathrm{mol} . \mathrm{K}) ; \Delta G$ is Gibbs free energy $(\mathrm{kJ} / \mathrm{mol})$. Table 4 listed the value of these parameters. As a results in Table 5, the low to

Table 4. MG adsorption by several adsorbents comparison.

\begin{tabular}{lccc}
\hline Adsorbents & $\begin{array}{c}\text { Adsorption condition } \\
\mathrm{pH}\end{array}$ & $\begin{array}{c}\text { MG adsorption capacity } \\
(\mathrm{mg} / \mathrm{g})\end{array}$ & Ref. \\
\hline Pristine Lignin & 2 & 31.2 & {$[22]$} \\
Neem Sawdust & 7.2 & 4.35 & {$[23]$} \\
Ginger Waste & 9 & 84.3 & {$[24]$} \\
Novel Graphene Oxide & 2.6 & 113.5 & {$[25]$} \\
Red Clay & 5.16 & 64.75 & {$[26]$} \\
NiFe Intercalated POM LDH & - & 8.81 & {$[27]$} \\
Activated Carbon Lime & - & 47.0 & {$[28]$} \\
Ca/Al LDH & - & 70.42 & This work \\
Rice Husk BC & - & 51.02 & This work \\
Ca/Al-Biochar & - & 71.429 & This work \\
\hline
\end{tabular}

\begin{tabular}{|c|c|c|c|c|c|}
\hline Concentration & $T(\mathrm{~K})$ & $Q_{\mathrm{e}}(\mathrm{mg} / \mathrm{g})$ & $\Delta \mathrm{H}(\mathrm{kJ} / \mathrm{mol})$ & $\Delta \mathrm{S}(\mathrm{J} / \mathrm{mol} . \mathrm{K})$ & $\Delta \mathrm{G}(\mathrm{kJ} / \mathrm{mol})$ \\
\hline \multirow{4}{*}{$\mathrm{BC}$} & 303 & 35.077 & \multirow{4}{*}{13.914} & \multirow{4}{*}{4.600} & -0.029 \\
\hline & 313 & 38.526 & & & -0.489 \\
\hline & 323 & 41.260 & & & -0.950 \\
\hline & 333 & 43.639 & & & -1.410 \\
\hline \multirow{4}{*}{$\mathrm{Ca} / \mathrm{Al} \mathrm{LDH}$} & 303 & 36.504 & \multirow{4}{*}{26.404} & \multirow{4}{*}{8.880} & -0.186 \\
\hline & 313 & 42.212 & & & -1.063 \\
\hline & 323 & 46.492 & & & -1.941 \\
\hline & 333 & 51.861 & & & -2.819 \\
\hline \multirow{4}{*}{$\mathrm{Ca} / \mathrm{Al}-\mathrm{Biochar}$} & 303 & 50.297 & \multirow{4}{*}{52.029} & \multirow{4}{*}{17.78} & -1.971 \\
\hline & 313 & 55.309 & & & -3.754 \\
\hline & 323 & 60.363 & & & -5.536 \\
\hline & 333 & 66.227 & & & -7.318 \\
\hline
\end{tabular}

Table 5. Adsorption thermodynamic parameter. 
high adsorption energy was obtained, which was related to the adsorption belongs chemisorption. The enthalpy of $\mathrm{Ca} / \mathrm{Al}$-Biochar was more than $40 \mathrm{~kJ} / \mathrm{mol}$ [31]. The negative value of $\Delta G$ at various temperatures implies the spontaneity adsorption process and it is favorable at high temperatures. The positive value of $\Delta S$ on $\mathrm{MG}$ adsorption by $\mathrm{Ca} / \mathrm{Al} \mathrm{LDH}$, $\mathrm{BC}$ and $\mathrm{Ca} / \mathrm{Al}-\mathrm{Biochar}$ had corresponded to the randomness of the solid-liquid interface during the adsorption process. The positive value of $\Delta \mathrm{H}$ indicated the reaction of adsorption become endothermic due to the dye adsorbed was an increase on increasing temperature. The $\mathrm{Ca} / \mathrm{Al}$-Biochar had the highest value indicated that the interaction between adsorbate and adsorbent was more effective of MG adsorption.

\section{Conclusions}

In conclusion, the $\mathrm{Ca} / \mathrm{Al} \mathrm{LDH}, \mathrm{BC}$, and $\mathrm{Ca} / \mathrm{Al}$-Biochar were successfully prepared and applied to selective adsorption of MG toward cationic $\mathrm{MB}$ and Rh-B. The selectivity study showed that MG was more selective than MB and Rh-B for all adsorbent. MB was removed entirely after $90 \mathrm{~min}$. The MG adsorption kinetics was followed the PSO model with a coefficient correlation closed to one. The adsorption isotherms could be expertly matched using the Langmuir model. The adsorption capacity of $\mathrm{MG}$ onto $\mathrm{Ca} / \mathrm{Al}-\mathrm{Biochar}, \mathrm{Ca} / \mathrm{Al} \mathrm{LDH}$, and $\mathrm{BC}$ were $71.429 \mathrm{mg} / \mathrm{g}, 70.423 \mathrm{mg} / \mathrm{g}$, and 51.020 $\mathrm{mg} / \mathrm{g}$, respectively. The thermodynamic analysis indicates that the $\mathrm{MG}$ adsorption in all adsorbents was spontaneous $(\Delta G<0)$, endothermic, the randomness of solid-liquid phase interface and the adsorption process was belonged to chemisorption.

\section{Acknowledgment}

Authors deeply appreciated Universitas Sriwijaya through Hibah Profesi 2020-2021 for financial support of this research with contract no. 0687/UN9/SK.BUK.KP/2020. Authors also thank Research Center of Inorganic Materials and Complexes FMIPA Universitas Sriwijaya for laboratory equipment and analysis of materials.

\section{References}

[1] Lellis, B., Fávaro-Polonio, C.Z., Pamphile, J.A., Polonio, J.C. (2019). Effects of textile dyes on health and the environment and bioremediation potential of living organisms. Biotechnology Research and Innovation, 3, 275290. DOI: 10.1016/j.biori.2019.09.001
[2] Khan, S.A., Khan, S.B., Asiri, A.M. (2016). Layered double hydroxide of $\mathrm{Cd}-\mathrm{Al} / \mathrm{C}$ for the Mineralization and De-coloration of Dyes in Solar and Visible Light Exposure. Scientific Reports, 6, 14-18. DOI: 10.1038/srep35107

[3] Yong, S., Choi, J., Guen, K., Choi, K., Jae, Y., Jung, K. (2019). Adsorption and mechanistic study for phosphate removal by rice huskderived biochar functionalized with $\mathrm{Mg} / \mathrm{Al}$ calcined layered double hydroxides via copyrolysis. Composites Part B, 176, 107209. DOI: 10.1016/j.compositesb.2019.107209

[4] Pokhriyal, M., Yadav, D.K., Pal, S., Uma, S., Nagarajan, R. (2019). Rapid and One-Step Transformation of LiAlH4 to Inorganic and Organic Anion Intercalated Li-Al Layered Double Hydroxides. European Journal of Inorganic Chemistry, 2019, 2412-2418. DOI: 10.1002/ejic.201900111

[5] Segun-Esan, O. (2019). The Removal of Single and Binary Basic Dyes from Synthetic Wastewater Using Bentonite Clay Adsorbent. American Journal of Polymer Science and Technology, $5, \quad 16$. D O I : 10.11648/j.ajpst.20190501.13

[6] Tonato, D., Drumm, F.C., Grassi, P., Georgin, J., Gerhardt, A.E., Dotto, G.L., Mazutti, M.A. (2019). Residual biomass of Nigrospora sp. from process of the microbial oil extraction for the biosorption of procion red $\mathrm{H}-\mathrm{E} 7 \mathrm{~B}$ dye. Journal of Water Process Engineering, 31, 100818. DOI: $10.1016 /$ j.jwpe.2019.100818

[7] León, O., Muñoz-Bonilla, A., Soto, D., Pérez, D., Rangel, M., Colina, M., Fernández-García, M. (2018). Removal of anionic and cationic dyes with bioadsorbent oxidized chitosans. Carbohydrate Polymers, 194, 375-383. DOI: 10.1016/j.carbpol.2018.04.072

[8] Banerjee, S., Chattopadhyaya, M.C. (2017). Adsorption characteristics for the removal of a toxic dye, tartrazine from aqueous solutions by a low cost agricultural by-product. Arabian Journal of Chemistry, 10, S1629-S1638. DOI: 10.1016/j.arabjc.2013.06.005

[9] Altaf, M., Ahmad, N., Cheng, C., Shoaib, S., Shah, A. (2020). Applied Clay Science Surface induced growth of ZIF-67 at Co-layered double hydroxide: Removal of methylene blue and methyl orange from water. Applied Clay Science, $190, \quad 105564$. DOI: 10.1016/j.clay.2020.105564

[10] Garg, V.K.K.R., Gupta, R. (2004). Removal of malachite green dye from aqueous solution by adsorption using agro-industry waste: a case study of Prosopis cineraria. Dyes Pigments, 62, 1-10. DOI: 10.1016/S0143-7208(03)002249

[11] Palapa, N.R., Taher, T., Rahayu, B.R., Mohadi, R., Rachmat, A., Lesbani, A. (2020). $\mathrm{CuAl}$ LDH/Rice Husk Biochar Composite for 
Enhanced Adsorptive Removal of Cationic Dye from Aqueous Solution. Bulletin of Chemical Reaction Engineering \& Catalysis, 15(2), 525-537. DOI: 10.9767/bcrec.15.2.7828.525537

[12] Daud, M., Hai, A., Banat, F., Wazir, M.B., Habib, M., Bharath, G., Al-Harthi, M.A. (2019). A review on the recent advances, challenges and future aspect of layered double hydroxides (LDH) - Containing hybrids as promising adsorbents for dyes removal. Journal of Molecular Liquids, 288, 110989. DOI: 10.1016/j.molliq.2019.110989

[13] Kumar, P.A., Stanley, J., Babu, T.G.S., Suneesh, P.V. (2018). Synthesis of NickelAluminium Layered Double Hydroxide and itsApplication in Non-Enzymatic Glucose Sensing. Materials Today: Proceedings, 5, $\begin{array}{llllllllllllll}1 & 6 & 1 & 2 & 5 & - & 1 & 6 & 1 & 3 & 1\end{array}$. $\quad$ D O I : 10.1016/j.matpr.2018.05.098

[14] Li, Y., Bi, H.Y., Liang, Y.Q., Mao, X.M., Li, H. (2019). A magnetic core-shell dodecyl sulfate intercalated layered double hydroxide nanocomposite for the adsorption of cationic and anionic organic dyes. Applied Clay Science, 183, 105309. DOI: 10.1016/j.clay.2019.105309

[15] Mominarafatullah, M., Ismail, S., Ahmad, A. (2019). Optimization study for the desorption of methylene blue dye from clay based adsorbent coating. Water (Switzerland), 11(6), 1304. DOI: $10.3390 / w 11061304$

[16] Meili, L., Lins, P. V., Zanta, C.L.P.S., Soletti, J.I., Ribeiro, L.M.O., Dornelas, C.B., Silva, T.L., Vieira, M.G.A. (2019). MgAlLDH/Biochar composites for methylene blue removal by adsorption. Applied Clay Science, 168, 11-20. DOI: 10.1016/j.clay.2018.10.012

[17] Palapa, N.R., Saria, Y., Taher, T., Mohadi, R., Lesbani, A. (2019). Synthesis and Characterization of $\mathrm{Zn} / \mathrm{Al}, \mathrm{Zn} / \mathrm{Fe}$, and $\mathrm{Zn} / \mathrm{Cr}$ Layered Double Hydroxides: Effect of M3+ ions Toward Layer Formation. Science and Technology Indonesia, 4, 36-39. DOI: 10.26554/sti.2019.4.2.36-39

[18] Zhang, M., Gao, B., Yao, Y., Inyang, M. (2013). Phosphate removal ability of biochar/MgAl-LDH ultra-fine composites prepared by liquid-phase deposition. Chemosphere, 92, 1042-1047. DOI: 10.1016/j.chemosphere.2013.02.050

[19] Das, S., Dash, S.K., Parida, K.M. (2018). Kinetics, Isotherm, and Thermodynamic Study for Ultrafast Adsorption of Azo Dye by an Efficient Sorbent: Ternary $\mathrm{Mg} /(\mathrm{Al}+\mathrm{Fe})$ Layered Double Hydroxides. ACS Omega, 3, 25322545. DOI: 10.1021/acsomega.7b01807
[20] Wan, S., Wang, S., Li, Y., Gao, B. (2017). Functionalizing biochar with $\mathrm{Mg}-\mathrm{Al}$ and $\mathrm{Mg}-$ Fe layered double hydroxides for removal of phosphate from aqueous solutions. Journal of Industrial and Engineering Chemistry, 47, 246-253. DOI: 10.1016/j.jiec.2016.11.039

[21] Lee, S.L., Park, J.H., Kim, S.H., Kang, S.W., Cho, J.S., Jeon, J.R., Lee, Y.B., Seo, D.C. (2019). Sorption behavior of malachite green onto pristine lignin to evaluate the possibility as a dye adsorbent by lignin. Applied Biological Chemistry, 62, 37. DOI: 10.1186/s13765019-0444-2

[22] Khattri, S.D., Singh, M.K. (2009). Removal of malachite green from dye wastewater using neem sawdust by adsorption. Journal of Hazardous Materials, 167, 1089-1094. DOI: 10.1016/j.jhazmat.2009.01.101

[23] Ahmad, R., Kumar, R. (2010). Adsorption studies of hazardous malachite green onto treated ginger waste. Journal of Environmental Management, 91, 1032-1038. DOI: 10.1016/j.jenvman.2009.12.016

[24] Chen, H., Liu, T., Meng, Y., Cheng, Y., Lu, J., Wang, H. (2020). Novel graphene oxide/aminated lignin aerogels for enhanced adsorption of malachite green in wastewater. Colloids and Surfaces A: Physicochemical and Engineering Aspects, 603, 125281. DOI: 10.1016/j.colsurfa.2020.125281

[25] Sevim, F., Lacin, O., Ediz, E.F., Demir, F. (2020). Adsorption capacity, isotherm, kinetic, and thermodynamic studies on adsorption behavior of malachite green onto natural red clay. Environmental Progress and Sustainable Energy, 40(1), e13471. DOI: $10.1002 / \mathrm{ep} .13471$

[26] Lesbani, A., Taher, T., Palapa, N.R., Mohadi, R., Rachmat, A., Mardiyanto, M. (2020). Preparation and utilization of Keggin-type polyoxometalate intercalated $\mathrm{Ni}-\mathrm{Fe}$ layered double hydroxides for enhanced adsorptive removal of cationic dye. SN Applied Sciences, 2, 470. DOI: $10.1007 / \mathrm{s} 42452-020-2300-8$

[27] Ahmad, M.A., Afandi, N.S., Bello, O.S. (2017). Optimization of process variables by response surface methodology for malachite green dye removal using lime peel activated carbon. $A p$ plied Water Science, 7, 717-727. DOI: 10.1007/s13201-015-0284-0

[28] Karim, A.B., Mounir, B., Hachkar, M., Bakasse, M., Yaacoubi, A. (2017). Adsorption/desorption behavior of cationic dyes on Moroccan clay: Equilibrium and mechanism. Journal of Materials and Environmental Science, 8(3), 1082-1096. 